This PDF is a selection from an out-of-print volume from the National Bureau of Economic Research

Volume Title: Frontiers in Health Policy Research, Volume 4

Volume Author/Editor: Alan M. Garber, editor

Volume Publisher: MIT PRess

Volume ISBN: 0-262-57150-1

Volume URL: http://www.nber.org/books/garb01-1

Publication Date: January 2001

Chapter Title: Trends in the Use of Intensive Procedures at the End of Life

Chapter Author: Amber E. Barnato, Alan M. Garber, Christopher R. Kagay, Mark C. McClellan

Chapter URL: http://www.nber.org/chapters/c9853

Chapter pages in book: (p. 95 - 114) 


\title{
Trends in the Use of Intensive Procedures at the End of Life
}

\author{
Amber E. Barnato, Stanford University School of Medicine
}

Alan M. Garber, Veterans Affairs Palo Alto Health Care System

Stanford University

National Bureau of Economic Research, Inc.

Christopher R. Kagay, National Bureau of Economic Research, Inc.

Mark C. McClellan, Stanford University

National Bureau of Economic Research, Inc.

\section{Executive Summary}

Despite widely publicized changes in attitudes toward the care of the dying and rapid growth in hospice care and other services targeted toward the dying, a remarkably stable 30 percent of total Medicare expenditures is spent on the 5 percent of Medicare beneficiaries over the age of 65 who die each year (Lubitz and Riley 1993). Since spending on behalf of decedents has kept pace with that for survivors (at a pace steeply above the rate of inflation), it does not appear that services are being disproportionately withheld from, or applied to, the dying. It is unknown whether the increase in service intensity at the end of life-or indeed, among survivors-is associated with meaningful clinical or social gains.

According to numerous anecdotal reports, many Americans die in hospitals with aggressive medical intervention and insufficient pain control or psychological support (Nuland 1996). More comprehensive evidence comes from the longitudinal Study to Understand the Prognoses and Preferences for Outcomes and Risks of Treatments (SUPPORT), which was conducted in five U.S. teaching hospitals. SUPPORT revealed that 38 percent of patients who died spent at least ten days in an intensive care unit and half of conscious patients experienced moderate to severe pain at least half the time (SUPPORT 1995). However, a comprehensive review of Medicare costs in the last year of life found that "only a small proportion of decedents had the kind of high expenses that would suggest aggressive, high technology medical services such as the use of ICUs or respirators" (Scitovsky 1994).

Retrospective analyses of Medicare claims data from 1976 to 1995 show a steady decline in the proportion of Medicare costs in the last year of life spent for hospitalization and an increase in the proportion spent on home health care and hospice. These trends may be related to the introduction of reimbursement for those services or perhaps a more complex interplay of social, legislative, and economic forces. However, this shift has not slowed the rate of growth of total expenditures for end-of-life care (Garber, MaCurdy, and McClellan 1998). 
No published study to date has specifically evaluated trends in the use of aggressive technologies among dying Medicare beneficiaries. Drawing from a 20 percent sample of Medicare claims for decedents and a 5 percent sample of claims from survivors, we studied the use of forty-five intensive procedures among Medicare beneficiaries in 1985, 1990, and 1995.

Each of the procedures was performed more frequently among decedents than survivors, and the relative growth in the use of all forty-five procedures combined outpaced the rate of their use among survivors. However, a subset of procedures dependent on technologies introduced between 1985 and 1995 diffused less rapidly among decedents than survivors. Although a decedent is more likely to undergo an intensive procedure in any year, most procedures are performed in Medicare survivors because they vastly outnumber decedents. Exceptions include some life-support technologies: two-thirds of all intubations and tracheostomies performed among Medicare beneficiaries in 1995 were done in decedents, as were over half of all feeding-tube placements and cardiac-balloon assist devices.

Expenditures associated with hospitalizations in which these forty-five intensive procedures were performed grew faster than overall inpatient expenditures, contemporaneous with a shift of less intensive procedures from the inpatient to the outpatient setting. This trend in increasing intensity of treatment among both decedents and survivors contributes to expenditure growth that outpaces changes in demographics and disease incidence. Furthermore, the rapid growth in the use of intensive procedures among decedents may explain why increased use of less expensive services such as hospice and home health care for some decedents has done little to slow the growth rate of expenditures at the end of life.

\section{Introduction}

Discussion of rising Medicare costs often focuses on the steep rise in health care utilization that occurs as death nears. In their last year of life, Medicare beneficiaries generate expenditures about six times as great as for nondecedents, a ratio that has been remarkably constant over many years (Lubitz and Riley 1993). The disproportionately high expenditures that occur in the last year of life are sometimes interpreted to mean that much of the care provided is futile. However, it is not always possible to determine ex ante that the care will be futile-not everyone who receives expensive care was known to be terminally ill, and most of the people who receive such care survive. Furthermore, the introduction of services targeted toward end-of-life care, such as hospice and some forms of home health care, have not always been associated with reductions in overall Medicare expenditures for dying beneficiaries (Garber, MaCurdy, and McClellan 1998). Consequently, policies aimed at controlling end-of-life expenditures must be based on 
a precise identification of the services that are likely to be futile when administered to an identifiable group of Medicare beneficiaries.

A diverse array of medical services, ranging from home health care and basic outpatient services to major operations and intensive care, account for Medicare expenditures on behalf of dying beneficiaries. Some supportive services, like hospice care and aggressive pain management, are targeted toward dying patients. Increasing their use in the last year of life is widely considered to be desirable. However, other services, particularly intensive treatments like major operations, are of questionable value when administered at the end of life. They cannot be considered to have benefited a dying patient unless they palliate an incurable illness.

Little is known about the relative contributions of intensive procedures and palliative or terminal care to the growth of health expenditures of dying Medicare beneficiaries. Some studies suggest that end-of-life services, such as hospice, have had a limited role in slowing expenditure growth. The interpretation of the Medicare hospice benefit - which limits eligibility to beneficiaries with a life expectancy of less than six months-may contribute to underuse of hospice care because many conditions have an uncertain prognosis. Thus, beneficiaries who do not have a cancer diagnosis or a very severe chronic illness may receive hospice care for only days or weeks, if at all. For such beneficiaries, there may be little opportunity to use hospice services and to avoid hospitalizations and the use of other acute services (Christakis and Escarce 1996). Many other dying Medicare beneficiaries are not even referred to hospice.

Many dying beneficiaries receive intensive procedures. Decompositions of personal health care expenditure growth in the United States in recent decades consistently show that the "technology" or "volumeintensity" component is the most important of all the potentially controllable sources of growth. After controlling for demographic change and general price inflation, the volume-intensity component is the predominant cause of the increase in expenditures for intensive procedures because real prices for such procedures often stay relatively constant and may actually decrease over time (McClellan and Cutler 1996).

The volume-intensity component arises from the adoption of new and more expensive technologies, the addition of more (whether new or old) diagnostic and therapeutic services, or the substitution of more expensive services more generally. For example, if coronary artery 
bypass graft surgery is used to treat coronary artery disease in seventy-five-year-olds more often this year than last, and if the treatment does not replace another form of care that is more expensive, expenditures will rise, even though neither the available technologies nor the prices have changed. To the extent that intensive procedures are expensive procedures, increases in their use will raise expenditures.

Does a similar phenomenon contribute to the growth in end-of-life expenditures? If so, is a set of specific diagnostic or therapeutic services responsible for a large share of the expenditure growth?

To explore the relationship between treatment intensity and endof-life expenditures, we examine trends in the use of major intensive services at the end of life, comparing the experience and expenditures of decedents with that of Medicare beneficiaries who did not die during the corresponding time period. We focus specifically on Medicare-financed inpatient services in 1985, 1990, and 1995, a decade that began soon after Medicare introduced its Prospective Payment System for inpatient care and that ended at a time when the effects of managed care had been felt throughout the health care system.

\section{Methods}

Drawing upon a 20 percent random sample of Medicare beneficiaries in 1985, 1990, and 1995, we examined two cohorts: all decedents and a random sample of survivors corresponding to 5 percent of all Medicare beneficiaries. For each of the three years, we collected the Part A hospital claims for decedents in the 365 days preceding their death and for the survivors during the calendar year. We excluded any beneficiary who was younger than 65 years of age, who was not continuously enrolled in Medicare Part A or Part B during the year of study, who resided outside the United States, who was enrolled in a health maintenance organization for all or part of the year, or whose hospitalization occurred in a federal hospital (see Appendix 4.1). We assumed that hospital utilization records would be incomplete for these beneficiaries. We calculated summary statistics of inpatient procedure use and expenditures for decedents and survivors (SAS version 6.12, SAS Institute, Inc., Cary, North Carolina). Summary statistics for decedents include all hospitalizations in the last year of life and decedent hospitalizations.

We condensed the International Classification of Diseases, 9th Edition (ICD-9), procedure codes into 246 procedure categories that were clini- 
cally relevant and economically important for assessing intensive treatment near the end of life. For this study, we excluded 162 procedure categories that were very rare (such as heart transplantation), were ill-defined and likely to include highly varied procedures (such as miscellaneous categories), or were sometimes performed in the outpatient setting (such as colonoscopy). We excluded another forty-three therapeutic procedure categories that did not each contribute at least $\$ 100$ million to total Medicare inpatient expenditures in any of the three study years. Four new technologies introduced in the 1985-1995 period that did not meet this cost criterion were retained in our sample because they may diffuse more widely in subsequent years.

We assigned each of the remaining forty-five procedure categories into one of four classes: life-support procedures, ${ }^{1}$ diagnostic and therapeutic procedures that aim to cure disease or prevent a fatal or disabling outcome, ${ }^{2}$ procedures that aim to decrease symptoms and improve quality of life, ${ }^{3}$ and new technologies..$^{4}$ Some procedures have overlapping aims; for example, coronary artery bypass grafting (CABG) reduces symptoms of angina and decreases heart attack risk. In cases where procedures could be dually classified, we assigned the procedure to the category class that reflected its most common use in actual practice.

To compare the use of intensive procedures, we report the frequency of use and the associated expenditures for decedents and the corresponding decedent-to-survivor ratios for frequency and expenditures. We use the 1995 decedents as the reference population for direct age-, sex-, and race-adjustment of all summary statistics. We also report utilization rates for blacks versus nonblacks and men versus women. All expenditures are in 1995 dollars.

\section{Results}

The number of Medicare decedents in our sample grew slightly more than the number of survivors between 1985 and 1995 (10.3 percent versus 9.3 percent) (table 4.1 ). The average beneficiary age, for both survivors and decedents, rose during the decade, as did the proportion of blacks and women (table 4.1). Black decedents were much younger than nonblack decedents; their average age at death was $74.5 \mathrm{com}$ pared to 78.8 for nonblacks in 1995 (table 4.2). Blacks were overrepresented among decedents and accounted for a greater share of total inpatient expenditures than would be expected by their representation in 


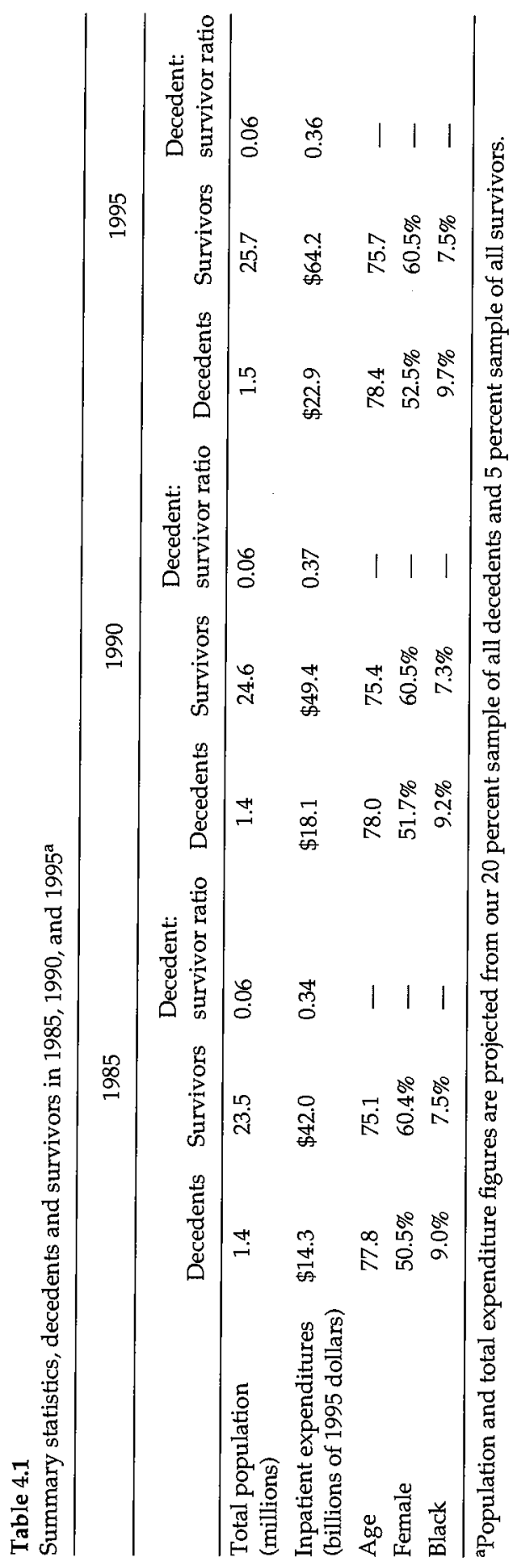


Table 4.2

Summary statistics, decedents and survivors in 1985, 1990, and 1995, by race ${ }^{a}$

\begin{tabular}{|c|c|c|c|c|c|c|}
\hline \multirow[b]{3}{*}{ Race } & \multicolumn{6}{|c|}{1985} \\
\hline & \multicolumn{2}{|c|}{ Decedents } & \multicolumn{2}{|c|}{ Survivors } & \multicolumn{2}{|c|}{$\begin{array}{l}\text { Decedent: } \\
\text { survivor ratio }\end{array}$} \\
\hline & Black & Nonblack & Black & Nonblack & Black & Nonblack \\
\hline $\begin{array}{l}\text { Total population } \\
\text { (thousands) }\end{array}$ & 113 & 1,250 & 1,807 & 21,675 & 0.06 & 0.06 \\
\hline $\begin{array}{l}\text { Inpatient } \\
\text { expenditures } \\
\text { (billions of } 1995 \\
\text { dollars) }\end{array}$ & $\$ 1.4$ & $\$ 12.9$ & $\$ 3.2$ & $\$ 38.7$ & 0.4 & 0.3 \\
\hline Age & 75.0 & 78.0 & 75.0 & 75.1 & - & - \\
\hline Female & $48.8 \%$ & $50.7 \%$ & $61.0 \%$ & $60.4 \%$ & - & - \\
\hline
\end{tabular}

\begin{tabular}{|c|c|c|c|c|c|c|}
\hline \multirow[b]{3}{*}{ Race } & \multicolumn{6}{|c|}{1990} \\
\hline & \multicolumn{2}{|c|}{ Decedents } & \multicolumn{2}{|c|}{ Survivors } & \multicolumn{2}{|c|}{$\begin{array}{c}\text { Decedent: } \\
\text { survivor ratio }\end{array}$} \\
\hline & Black & Nonblack & Black & Nonblack & Black & Nonblack \\
\hline $\begin{array}{l}\text { Total population } \\
\text { (thousands) }\end{array}$ & 118 & 1,280 & 1,861 & 22,727 & 0.06 & 0.06 \\
\hline $\begin{array}{l}\text { Inpatient } \\
\text { expenditures } \\
\text { (billions of } 1995 \\
\text { dollars) }\end{array}$ & $\$ 1.9$ & $\$ 16.1$ & $\$ 3.9$ & $\$ 45.4$ & 0.5 & 0.4 \\
\hline Age & 75.1 & 78.3 & 75.3 & 75.4 & - & - \\
\hline \multirow[t]{3}{*}{ Female } & $50.4 \%$ & $51.9 \%$ & $61.8 \%$ & $60.4 \%$ & 一 & - \\
\hline & \multicolumn{6}{|c|}{1995} \\
\hline & \multicolumn{2}{|c|}{ Decedents } & \multicolumn{2}{|c|}{ Survivors } & \multicolumn{2}{|c|}{$\begin{array}{c}\text { Decedent: } \\
\text { survivor ratio }\end{array}$} \\
\hline Race & Black & Nonblack & Black & Nonblack & Black & Nonblack \\
\hline $\begin{array}{l}\text { Total population } \\
\text { (thousands) }\end{array}$ & 133 & 1,371 & 1,952 & 23,717 & 0.07 & 0.06 \\
\hline $\begin{array}{l}\text { Inpatient } \\
\text { expenditures } \\
\text { (billions of } 1995 \\
\text { dollars) }\end{array}$ & $\$ 2.6$ & $\$ 20.2$ & $\$ 5.5$ & $\$ 58.6$ & 0.5 & 0.3 \\
\hline Age & 74.5 & 78.8 & 75.6 & 75.7 & - & - \\
\hline Female & $50.8 \%$ & $52.7 \%$ & $63.3 \%$ & $60.2 \%$ & - & - \\
\hline
\end{tabular}

apopulation and total expenditure figures are projected from our 20 percent sample of all decedents and 5 percent sample of all survivors. 
the decedent and survivor populations (tables 4.1 and 4.2). Among decedents and survivors, women accounted for more than half of the population and were older than men. Female decedents accounted for a greater share of inpatient expenditures than would be expected by their representation in the population, but female survivors accounted for a lesser share than would be expected (tables 4.1 and 4.3). Total inpatient expenditures for decedents and survivors combined rose from $\$ 56.3$ billion to $\$ 87.1$ billion in constant dollars between 1985 and 1995, with decedents accounting for just over one-quarter of total inpatient expenditures each year (table 4.1).

\section{Hospital Utilization}

Between 1985 and 1995, a period during which hospital utilization fell generally, the fraction of survivors who were admitted to the hospital at least once declined from 21.5 percent to 20.8 percent. Hospital use also fell among decedents, and fewer Medicare beneficiaries died in the hospital in 1995 than in 1985 (table 4.4). Intensive care unit (ICU) and coronary care unit (CCU) use became more common for both decedents and survivors, but the relative growth was faster among survivors (table 4.4). ICU use during the terminal hospitalization stayed relatively constant, at 40 percent between 1985 and 1995 (table 4.4). Among decedents, hospital, ICU, CCU, and intensive procedure use were higher among men than women in all three years (data not shown) and higher among blacks than nonblacks in 1990 and 1995 (table 4.5).

Hospitalization rates were roughly similar among female and male survivors in all three years, but men were more likely to be admitted to an ICU or CCU. Only 5.9 percent of women survivors were admitted to an ICU during 1995, while 7.5 percent of men had an ICU admission (data not shown). Black survivors were more likely than nonblacks to have at least one hospitalization in 1990 and 1995, and were more likely to use the ICU or CCU in those two years as well (table 4.5).

\section{Inpatient Expenditures}

Decedents accounted for a vastly disproportionate share of inpatient expenditures. They generated one-fourth of total inpatient expenditures in each of the three years, even though they constituted only 
Table 4.3

Summary statistics, decedents, and survivors in 1985, 1990, and 1995, by gender ${ }^{\text {a }}$

\begin{tabular}{|c|c|c|c|c|c|c|}
\hline & \multicolumn{6}{|c|}{1985} \\
\hline & \multicolumn{2}{|c|}{ Decedents } & \multicolumn{2}{|c|}{ Survivors } & \multicolumn{2}{|c|}{$\begin{array}{c}\text { Decedent: } \\
\text { survivor ratio }\end{array}$} \\
\hline & Men & Women & Men & Women & Men & Women \\
\hline $\begin{array}{l}\text { Total population } \\
\text { (thousands) }\end{array}$ & 646 & 717 & 9,304 & 14,178 & 0.07 & 0.05 \\
\hline $\begin{array}{l}\text { Inpatient } \\
\text { expenditures } \\
\text { (billions of } 1995 \\
\text { dollars) }\end{array}$ & $\$ 7.0$ & $\$ 7.3$ & $\$ 17.5$ & $\$ 24.2$ & 0.4 & 0.3 \\
\hline Age & 75.4 & 80.0 & 74.1 & 75.5 & - & - \\
\hline \multirow[t]{4}{*}{ Black } & $9.4 \%$ & $8.7 \%$ & $7.4 \%$ & $7.5 \%$ & - & - \\
\hline & \multicolumn{6}{|c|}{1990} \\
\hline & \multicolumn{2}{|c|}{ Decedents } & \multicolumn{2}{|c|}{ Survivors } & \multicolumn{2}{|c|}{$\begin{array}{c}\text { Decedent: } \\
\text { survivor ratio }\end{array}$} \\
\hline & Men & Women & Men & Women & Men & Women \\
\hline $\begin{array}{l}\text { Total population } \\
\text { (thousands) }\end{array}$ & 642 & 755 & 9,722 & 14,866 & 0.07 & 0.05 \\
\hline $\begin{array}{l}\text { Inpatient } \\
\text { expenditures } \\
\text { (billions of } 1995 \\
\text { dollars) }\end{array}$ & $\$ 8.6$ & $\$ 9.5$ & $\$ 20.4$ & $\$ 28.7$ & 0.4 & 0.3 \\
\hline Age & 75.6 & 80.3 & 74.4 & 76.0 & 一 & - \\
\hline \multirow[t]{4}{*}{ Black } & $9.4 \%$ & $8.9 \%$ & $7.1 \%$ & $7.5 \%$ & - & - \\
\hline & \multicolumn{6}{|c|}{1995} \\
\hline & \multicolumn{2}{|c|}{ Decedents } & \multicolumn{2}{|c|}{ Survivors } & \multicolumn{2}{|c|}{$\begin{array}{l}\text { Decedent: } \\
\text { survivor ratio }\end{array}$} \\
\hline & Men & Women & Men & Women & Men & Women \\
\hline $\begin{array}{l}\text { Total population } \\
\text { (thousands) }\end{array}$ & 674 & 829 & 10,162 & 15,508 & 0.07 & 0.05 \\
\hline $\begin{array}{l}\text { Inpatient } \\
\text { expenditures } \\
\text { (billions of } 1995 \\
\text { dollars) }\end{array}$ & $\$ 10.5$ & $\$ 12.4$ & $\$ 25.7$ & $\$ 38.5$ & 0.4 & 0.3 \\
\hline Age & 75.7 & 80.8 & 74.6 & 76.4 & - & 一 \\
\hline Black & $10.0 \%$ & $9.3 \%$ & $6.9 \%$ & $7.9 \%$ & - & - \\
\hline
\end{tabular}

apopulation and total expenditure figures are projected from our 20 percent sample of all decedents and 5 percent sample of all survivors. 


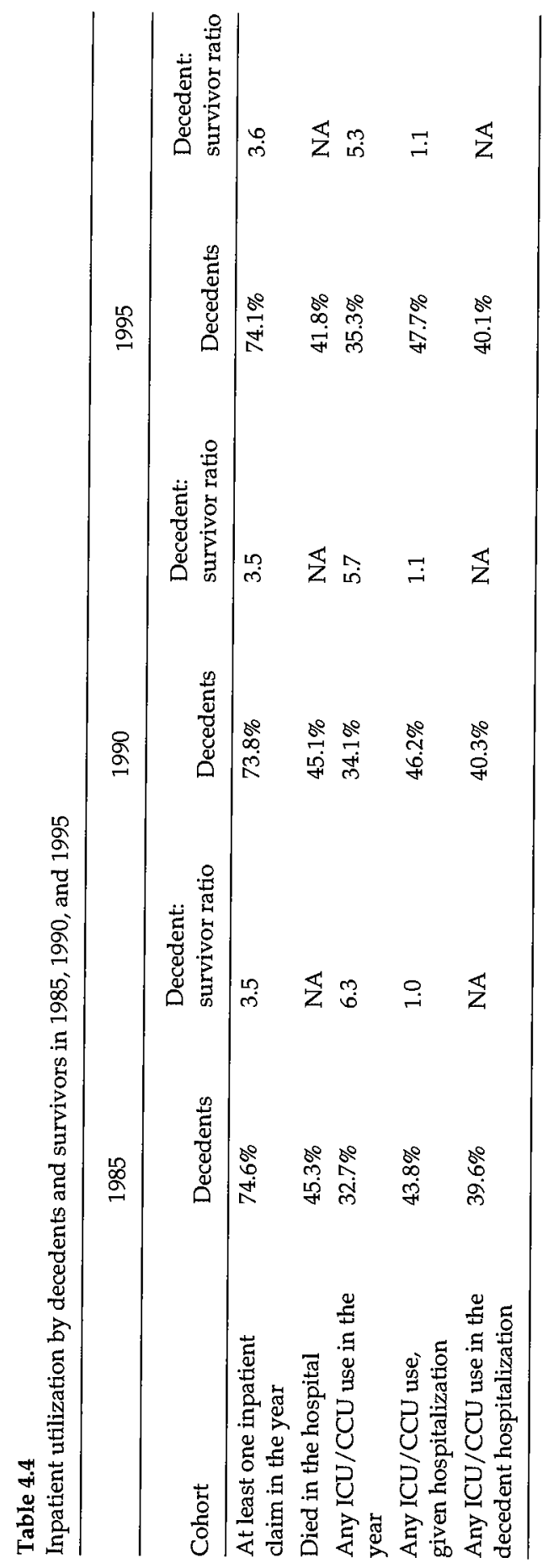




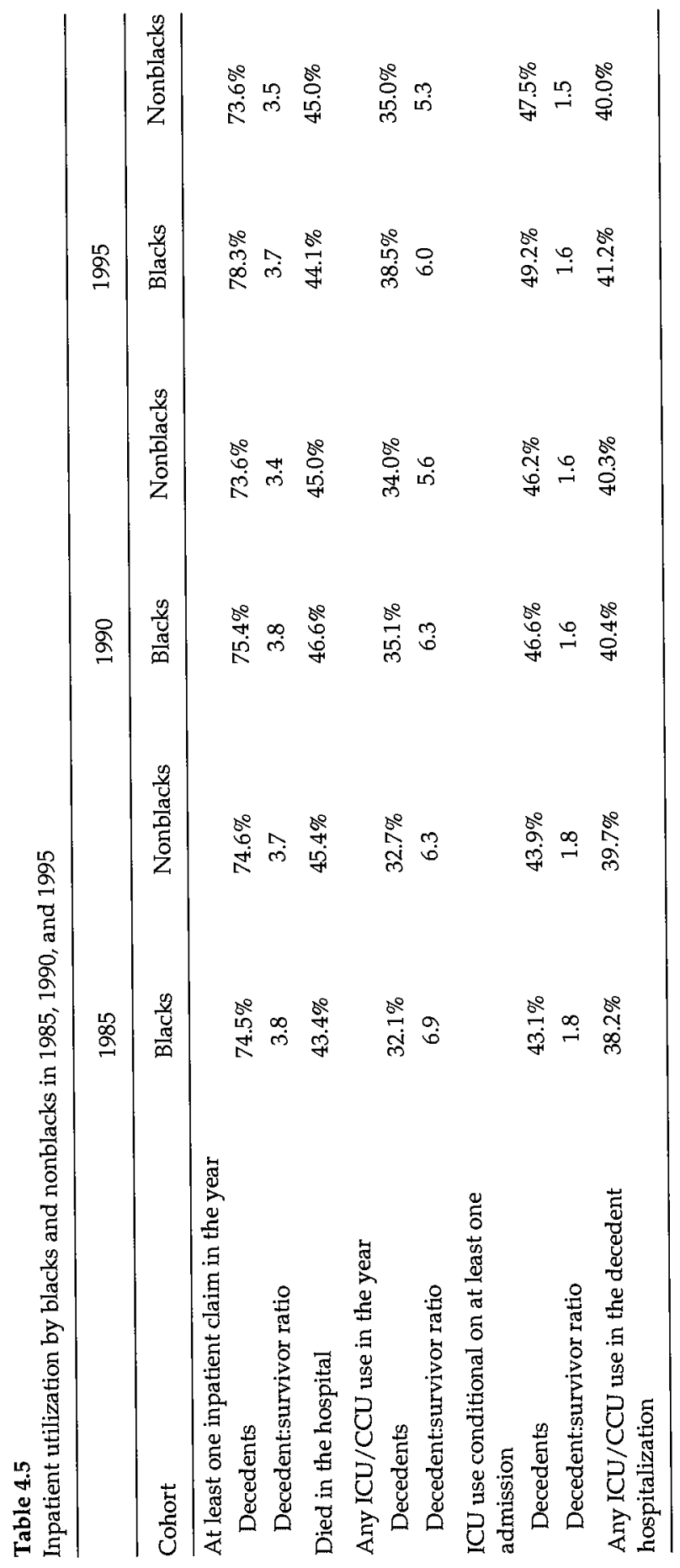


about 5.5 percent of the Medicare population. In 1985, inpatient expenditures per decedent were 5.9 times as high as for survivors, a ratio that rose to 6.2 in 1995 (figure 4.1).

Once admitted to the hospital, decedents generated inpatient expenditures that were 1.4 times higher in 1985 and 1.6 times higher in 1995 than for hospitalized survivors (figure 4.2). Higher expenditures reflected both a larger number of admissions per beneficiary who was hospitalized during a year, and expenditures per admission that were 10 to 20 percent higher.

Real inpatient expenditures for survivors and decedents combined rose 56 percent between 1985 and 1995, a period when the number of Medicare beneficiaries in our sample grew by only 9.4 percent. Per capita inpatient expenditures grew 45 percent among decedents and 40 percent among survivors. Conditional on at least one hospitalization in the year, per-person inpatient expenditures grew 46 percent for decedents and 33 percent for survivors between 1985 and 1995, and perclaim expenditures grew 25 percent among decedents and 23 percent among survivors.

\section{Intensive Procedure Use and Associated Expenditures}

Use of intensive procedures by decedents grew from 33 percent in 1985 to 57 percent in 1995, an increase of 70 percent over the decade

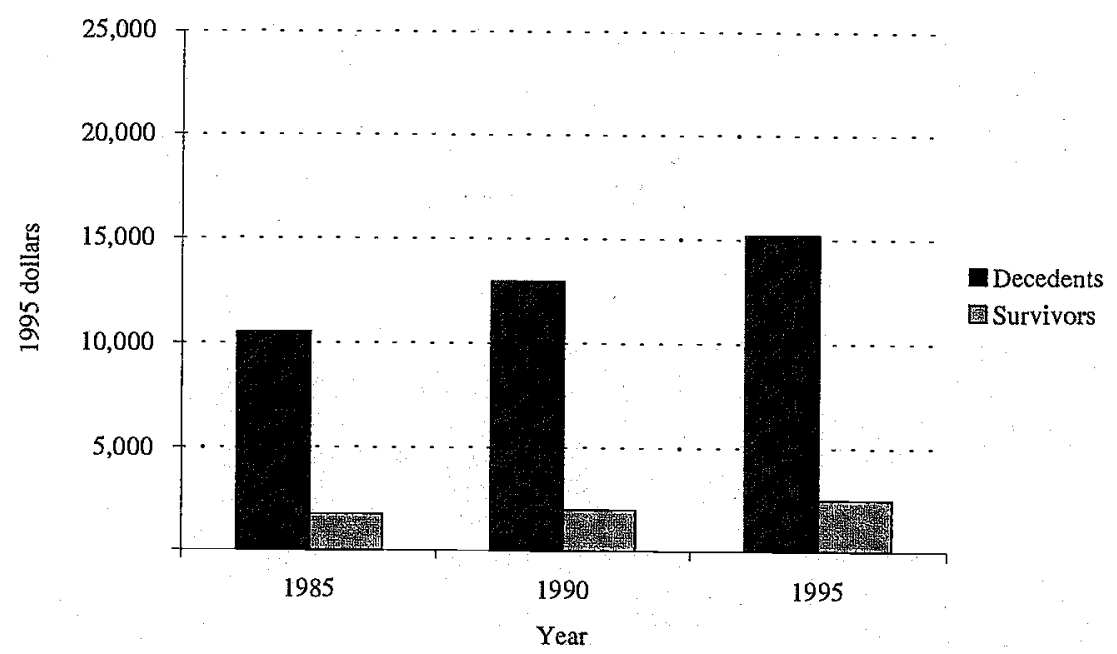

Figure 4.1

Per-person inpatient expenditures, all beneficiaries 


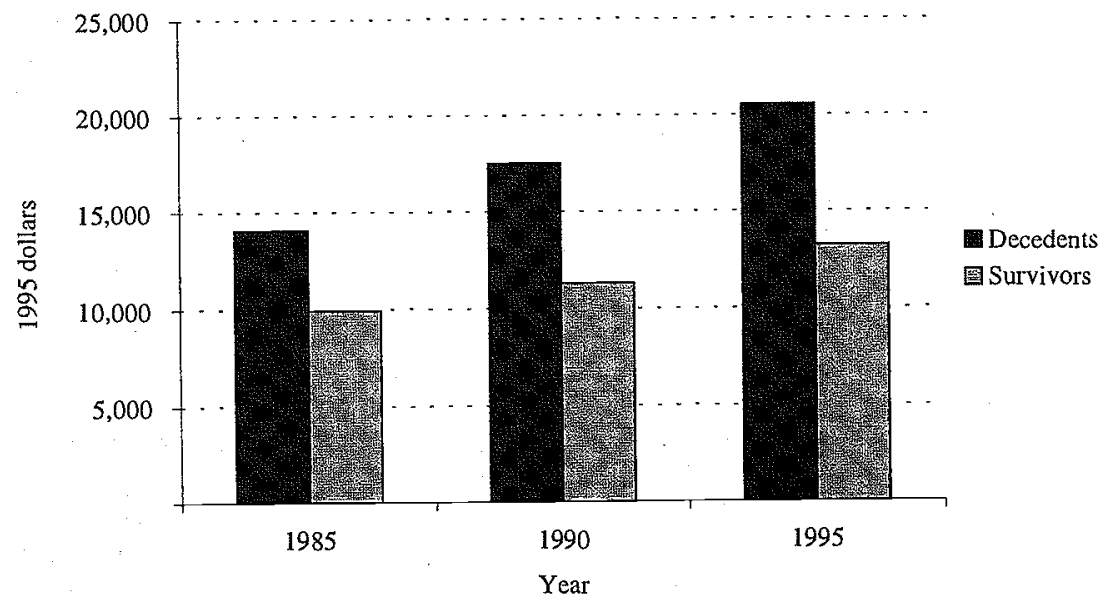

Figure 4.2

Per-person inpatient expenditures, conditional on at least one hospitalization

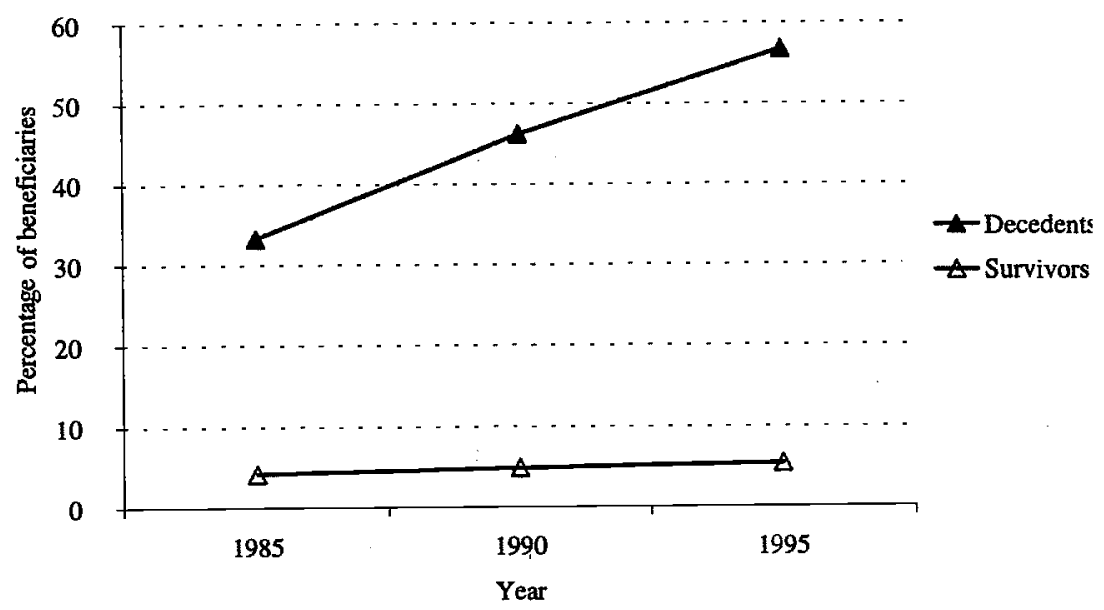

Figure 4.3

Trends in the use of intensive procedures among decedents and survivors, 1985, 1990, and 1995 
Table 4.6

Intensive procedure use, 1985, 1990, and 1995

\begin{tabular}{lrrrrrr}
\hline & \multicolumn{2}{c}{ Frequency among decedents } & \multicolumn{2}{c}{ Decedent:survivor ratio } \\
\hline Procedure & \multicolumn{1}{c}{1985} & 1990 & 1995 & 1985 & 1990 & 1995 \\
\hline All intensive procedures & $33.3 \%$ & $46.2 \%$ & $56.7 \%$ & 8.0 & 9.5 & 10.5 \\
Life support & $7.4 \%$ & $16.7 \%$ & $22.4 \%$ & 36.3 & 41.9 & 39.9 \\
Curative/preventive & $21.8 \%$ & $22.0 \%$ & $23.8 \%$ & 8.0 & 9.0 & 10.1 \\
Quality of life & $3.8 \%$ & $6.7 \%$ & $8.5 \%$ & 3.1 & 3.5 & 3.9 \\
New technology & $0.3 \%$ & $0.8 \%$ & $2.0 \%$ & 8.5 & 8.8 & 6.8 \\
\hline
\end{tabular}

(table 4.6, figure 4.3). In contrast, intensive procedure use among survivors increased only 29 percent during the same time period, growing from 4.2 percent in 1985 to 5.4 percent in 1995 (table 4.6, figure 4.3). Thus, the decedent-to-survivor ratio of intensive procedure use rose from 8.0 in 1985 to 10.5 in 1995 (table 4.6). Although decedents were more likely than survivors to undergo an intensive procedure, the majority of procedures were performed in the far more numerous survivors (table 4.7).

The admissions associated with these intensive procedures accounted for 23 percent, 34 percent, and 34 percent of total expenditures by decedents and 27 percent, 34 percent, and 33 percent of total inpatient expenditures by survivors in 1985, 1990, and 1995, respectively. Total hospital expenditures associated with intensive procedures grew from $\$ 3.3$ billion to $\$ 7.8$ billion in constant dollars between 1985 and 1995 among decedents, and from $\$ 11.3$ to $\$ 21.4$ billion among survivors. Thus, the decedent-to-survivor ratio of per-capita inpatient expenditures for hospitalizations associated with these intensive procedures rose from 5.0 to 6.2 during a decade when the ratio of the overall number of decedents to the number of survivors stayed constant (figure 4.4).

The percentage of decedents receiving life-support procedures rose from 7.4 percent in 1985 to 22.4 percent in 1995 (table 4.6). Over the same time period, the rate of life support procedure use among survivors grew from 0.2 percent to 0.6 percent. The decedent-to-survivor ratio increased from 36.3 in 1985, peaked at 41.9 in 1990, and dropped slightly to 39.9 in 1995 (table 4.6). Decedents accounted for most of the life-support procedures for Medicare beneficiaries in each year (table 4.7). 
Table 4.7

Proportion of all procedures done in decedents, 1985, 1990, and 1995

\begin{tabular}{lccr}
\hline & \multicolumn{2}{l}{ Procedures among decedents/all procedures performed in the } \\
\cline { 2 - 4 } year & 1985 & 1990 & 1995 \\
Procedure & $20 \%$ & $20 \%$ & $21 \%$ \\
\hline All intensive procedures & $58 \%$ & $59 \%$ & $58 \%$ \\
Life support & $21 \%$ & $20 \%$ & $21 \%$ \\
Curative/preventive & $9 \%$ & $9 \%$ & $9 \%$ \\
Quality of life & $22 \%$ & $21 \%$ & $15 \%$ \\
New technology & &
\end{tabular}

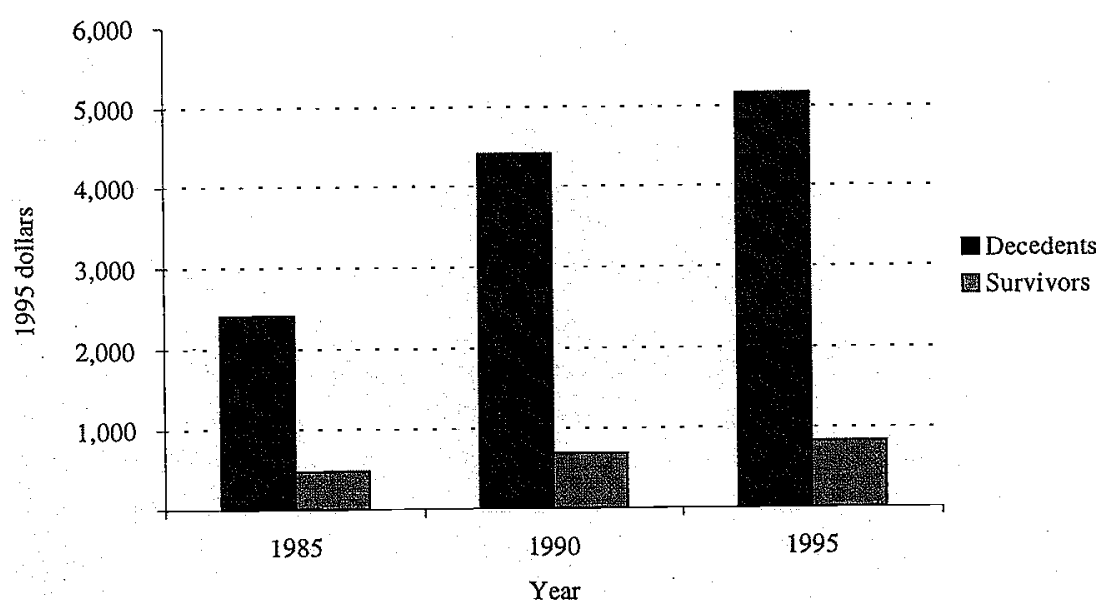

Figure 4.4

Per-person expenditures attributable to intensive-procedure hospitalizations

In 1985,22 percent of decedents and 2.7 percent of survivors underwent an intensive procedure that aimed to cure disease or prevent a disabling or fatal outcome; in 1995 the proportions were 24 percent and 2.4 percent, respectively (table 4.6). The decedent-to-survivor ratio for curative and preventive procedures increased from 8 in 1985 to 10 in 1995 (table 4.6). About 20 percent of these procedures were performed on decedents in each year (table 4.7).

Quality-of-life procedures were performed in 3.8 percent of decedents in 1985 and 8.5 percent of decedents in 1995 (table 4.6). Among survivors, the rate of quality-of-life procedure use grew from 1.2 percent to 2.2 percent over the decade. The decedent-to-survivor ratio 
increased from 3.1 to 3.9 over that time period (table 4.6). Only one in ten of these procedures were performed in decedents in each year (table 4.7).

In $1985,0.3$ percent of decedents and 0.03 percent of survivors underwent a procedure using one of five new technologies: automated implantable cardioverter defibrillators (AICD); endoscopic retrograde cholangiopancreatography (ERCP); electophysiology study (EPS); laparoscopic cholecystectomy; and stereotactic, percutaneous brain biopsy. In 1995, the fraction of decedents who underwent these procedures rose to 2 percent, while the fraction of survivors receiving these procedures rose to 0.3 percent. The relative increase in use occurred more rapidly among survivors than decedents (table 4.6), and the proportion of new procedures done in decedents fell over the decade (table 4.7).

\section{Discussion}

Between 1985 and 1995, a stable 5.5 percent of Medicare beneficiaries over the age of 65 died each year, and they accounted for a constant 25 percent of all inpatient expenditures. Hospitalization became less common during the decade, but the use of intensive care units and intensive inpatient procedures grew. Intensive care unit use grew more rapidly among survivors, but intensive procedure use grew more rapidly among decedents. Real per-capita inpatient expenditures grew over the decade, as did expenditures specifically attributable to hospitalizations associated with intensive procedures, with the growth among decedents outpacing that among survivors.

The greater growth in intensive procedure use and expenditures among decedents may explain in part a current health policy puzzle: why did the displacement of acute care hospital use by hospice and home health care between 1988 and 1995 fail to reduce the growth in Medicare expenditures at the end of life (Garber, MaCurdy, and McClellan 1998)? Our results suggest that Medicare beneficiaries who die in the hospital, despite constituting a declining percentage of Medicare decedents overall, are being treated more intensively and expensively. Our study design does not enable us to determine whether increases in the use of intensive procedures improved survival among the sickest Medicare beneficiaries.

The appropriateness of end-of-life expenditures cannot be judged solely by survival rates among individuals who receive intensive treat- 
ments. One intensive treatment that diffused rapidly in the $1990 \mathrm{~s}$ is the automatic internal cardioverter defibrillator (AICD). This expensive device, which requires an operation for implantation, was developed for the treatment of patients at high risk for developing a cardiac arrhythmia (irregularity of the heartbeat) that can lead to sudden cardiac death. It is more expensive than alternative treatments, but randomized controlled clinical trials have demonstrated that it is also more effective. Alternative treatments include Medicare-covered services such as hospital and office visits for arrhythmia and noncovered forms of treatment such as medications (Owens et al. 1997). The AICD is most effective if it is used in patients at the highest risk for sudden cardiac death; although the risk of death is lower with the device than with alternative treatments, such patients remain at high risk of death even if they receive an $\mathrm{AICD}$. If the device is targeted toward individuals who are most likely to benefit, it will appear to be a procedure that is disproportionately used in decedents.

Like the AICD, any highly effective technology can be used more frequently in decedents than survivors. Its use in decedents is not necessarily a sign of futile care. If AICD use grew rapidly among lower risk patients, for whom there may be modest clinical benefits, usage would shift increasingly toward survivors, as was observed in this study. This shift may actually reflect less cost-effective use of the device.

In contrast to life-support, curative/preventive, and quality-of-life procedures that grew more rapidly among decedents, the use of new-technology intensive procedures grew faster among survivors. The proportion of all procedures done each year for decedents stayed relatively constant for life-support, curative/preventive, and quality-of-life procedures, but the proportion of new-technology procedures done in decedents dropped from 22 percent in 1985 to 15 percent in 1995. This drop may represent a tendency to pioneer new technologies among the sickest patients before wider dissemination among those with less serious illnesses.

A subset of procedures is often considered emblematic of the care of dying patients. These procedures include intubation and tracheostomy, feeding tube placement, invasive hemodynamic monitoring, hemodialysis, and cardiac balloon assist devices. In 1995, 12 percent of decedents were intubated, 5 percent received a feeding tube, 3 percent had invasive hemodynamic monitoring, 2 percent were dialyzed in the hospital, and almost 1 percent had a cardiac balloon assist device placed 
inside their aortas during their last year; a full 20 percent who died in the hospital were on mechanical ventilation during that terminal hospitalization. The total inpatient expenditure for these services rose in constant dollars from $\$ 520$ million in 1985 to $\$ 3.2$ billion in 1995, a period during which the total number of decedents changed little. When these procedures are initiated in the hospital, the patient will often die in the next year.

These observations are based solely on enrollees in fee-for-service Medicare, and it is possible that the pattern of procedure use was different for Medicare beneficiaries enrolled in "risk plans," under which capitation is expected to diminish the use of both hospital care and intensive procedures. It is possible that Medicare managed care would target services more precisely toward survivors, but to the extent that they deliver more cost-effective care, the opposite might occur for some procedures such as AICD placement.

Between 1985 and 1995, per-person hospital use declined slightly, but the use of intensive procedures and intensive care units grew, with a higher relative increase in intensive procedure use among decedents than among survivors. Inpatient expenditures rose much faster than would be predicted by changing demographics and disease patterns of the Medicare population, which reflects the increased use of existing treatments and the dissemination of new ones. Decedents and survivors are being treated more intensively now than in the past, and decedents disproportionately so. These findings do not establish whether physicians are better able to target procedures to those who are most likely to benefit from them, but they suggest that there has not been any diminution in the aggressiveness of treatment of fee-for-service Medicare beneficiaries in the last year of life.

\section{Notes}

This research was supported in part by grants AG17253 and AG05842 from the National Institute on Aging and by the Homer Laughlin Endowment. Amber Barnato was supported by training grant T32 HSO0028 from the Agency for Healthcare Research and Quality to Stanford University.

1. Cardiac balloon assist device, feeding tube placement, inpatient hemodialysis, intubation and tracheostomy, right heart catheterization for the purposes of invasive hemodynamic monitoring.

2. Amputation of the leg, aortic repair, arteriogram, colon resection, hemodialysis shunt placement, excision and lysis of peritoneal tissue, exploratory laparotomy, laparoscopy, 
hysterectomy, ileostomy and colostomy, abdominal wall repair, lobectomy, mastectomy, nephrectomy, open bladder surgery, open cholecystectomy, open brain biopsy or surgery, open control of upper GI bleeding, gastrectomy, peripheral vascular bypass, peripheral vessel endarterectomy or thrombectomy, cardiac pacemaker insertion or revision, small bowel resection, treatment of hip or femur fracture, treatment of lower leg fracture, valve procedures, vena cava interruption.

3. Cardiac catheterization, coronary artery bypass graft, percutaneous transluminal coronary angiography, hip replacement, knee replacement, laminectomy and discectomy, transurethral prostatectomy.

4. AICD replacement or revision, diagnostic and therapeutic endoscopic retrograde cholangiopancreatography, electrophysiology study with and without radiofrequency ablation, laparoscopic cholecystectomy, percutaneous brain biopsy.

\section{References}

Christakis, N. A., and J. J. Escarce (1996). "Survival of Medicare Patients after Enrollment in Hospice Programs," New England Journal of Medicine 335 (3):172-178.

Garber, A. M., T. E. MaCurdy, and M. C. McClellan (1998). "Medical Care at the End of Life: Diseases, Treatment Patterns, and Costs." NBER Working Paper Series, Working Paper 6748:1-30.

Lubitz, J. D., and G. F. Riley (1993). "Trends in Medicare Payments in the Last Year of Life." New England Journal of Medicine, 328(15):1092-1096.

McClellan, M., and D. M. Cutler (1996). "The Determinants of Technological Change in Heart Attack Treatment." NBER Working Paper Series, Working Paper 5751:1-30.

Nuland, S. B. (1996). How We Die. New York, NY: Vintage Press.

Owens, D. K., G. D. Sanders, R. A. Harris, K. M. McDonald, P. A. Heidenreich, A. D. Dembitzer, M. A. Hlatky (1997). "Cost-Effectiveness of Implantable Cardioverter Defibrillators Relative to Amiodarone for Prevention of Sudden Cardiac Death," Annals of Internal Medicine 126 (1):1-12.

Scitovsky, A. A. (1994). "The High Cost of Dying" Revisited. Milbank Quarterly, 72(4):561-91.

SUPPORT (1995). "A Controlled Trial to Improve Care for Seriously Ill Hospitalized Patients: The Study to Understand Prognoses and Preferences for Outcomes and Risks of Treatment." Journal of the American Medical Association 274(20):1591-1598. 
Appendix 4.1

Exclusions from Study

\begin{tabular}{|c|c|c|c|c|c|c|}
\hline \multirow[b]{2}{*}{ Cohort } & \multicolumn{2}{|l|}{1985} & \multicolumn{2}{|l|}{1990} & \multicolumn{2}{|l|}{1995} \\
\hline & Decedents & Survivors & Decedents & Survivors & Decedents & Survivors \\
\hline Age $<65$ & 32,670 & 325,059 & 31,997 & 344,580 & 34,812 & 411,538 \\
\hline $\begin{array}{l}\text { Discontinuous } \\
\text { Part A enrollment }\end{array}$ & 332 & 3,886 & 941 & 11,325 & 808 & 7,017 \\
\hline $\begin{array}{l}\text { Discontinuous } \\
\text { Part B enrollment }\end{array}$ & 2,533 & 18,406 & 3,298 & 28,687 & 3,738 & 30,306 \\
\hline $\begin{array}{l}\text { Non-U.S. } \\
\text { resident }\end{array}$ & 2,315 & 2,087 & 4,254 & 3,333 & 8,684 & 6,386 \\
\hline $\begin{array}{l}\mathrm{HMO} \\
\text { membership }\end{array}$ & 989 & 84,626 & 15,542 & 152,038 & 26,862 & 233,386 \\
\hline $\begin{array}{l}\text { Federal hospital } \\
\text { claims }\end{array}$ & 16 & 10 & 14 & 11 & 3 & 6 \\
\hline
\end{tabular}

